(Supporting Information)

Enzymatic Degradation Processes of Lamellar Crystals in Thin Films for Poly $[(R)-3$-hydroxybutyric acid $]$ and its Copolymers Revealed by Real-Time

\title{
Atomic Force Microscopy
}

Keiji Numata, ${ }^{\dagger}$ Takuya Hirota, ${ }^{\dagger}$ Yoshihiro Kikkawa, ${ }^{\dagger}$ Takeharu Tsuge, ${ }^{\dagger}$ Tadahisa Iwata, ${ }^{\dagger}$ Hideki Abe, ${ }^{\dagger *}$ and Yoshiharu Doi* ${ }^{\dagger *}$

$\dagger$ Department of Innovative and Engineered Materials, Tokyo Institute of Technology, 4259 Nagatsuta, Midori-ku, Yokohama 226-8502, Japan and $\ddagger$ Polymer Chemistry Laboratory, RIKEN Institute, 2-1 Hirosawa, Wako-shi, Saitama 351-0198, Japan

\section{Caption for Figures}

\section{Figure S-1}

Length (a) distribution histograms of fiber-like crystals in melt-crystallized thin films of $\mathrm{P}(3 \mathrm{HB}) \quad(\mathrm{A}), \quad \mathrm{P}(3 \mathrm{HB}-c o-3 \mathrm{~mol} \% \quad 3 \mathrm{HH}) \quad(\mathrm{B}), \quad \mathrm{P}(3 \mathrm{HB}-c o-8 \mathrm{~mol} \% \quad 3 \mathrm{HH}) \quad(\mathrm{C})$, $\mathrm{P}(3 \mathrm{HB}-c o-10 \mathrm{~mol} \% 6 \mathrm{HH})(\mathrm{D}), \mathrm{P}(3 \mathrm{HB}-c o-6 \mathrm{~mol} \%$ 3HV) (E), and $\mathrm{P}(3 \mathrm{HB}-c o-14 \mathrm{~mol} \%$ 3HV) (F) after enzymatic degradation for $2 \mathrm{~h}$ by PHB depolymerase from $R$. pickettii $\mathrm{T} 1$ at $20{ }^{\circ} \mathrm{C}$. Each length was measured from AFM height images. In these frames, the total number of counts was 100 , respectively.

\section{Figure S-2}

Width (b1-b3) distribution histograms of fiber-like crystals at root (A-F(b1)), middle (A-F(b2)), and tip (A-F(b3)) in melt-crystallized thin films of $\mathrm{P}(3 \mathrm{HB})$ (A), $\mathrm{P}(3 \mathrm{HB}-c o-3 \mathrm{~mol} \%$ 3HH) (B), $\mathrm{P}(3 \mathrm{HB}-c o-8 \mathrm{~mol} \% 3 \mathrm{HH})(\mathrm{C}), \mathrm{P}(3 \mathrm{HB}-c o-10 \mathrm{~mol} \% 6 \mathrm{HH})$ (D), $\mathrm{P}(3 \mathrm{HB}-\mathrm{co}-6 \mathrm{~mol} \%$ 3HV) (E), and $\mathrm{P}(3 \mathrm{HB}-\mathrm{co}-14 \mathrm{~mol} \% 3 \mathrm{HV})(\mathrm{F})$ after enzymatic degradation for $2 \mathrm{~h}$ by PHB depolymerase from $R$. pickettii $\mathrm{T} 1$ at $20{ }^{\circ} \mathrm{C}$. Each width 
was determined from AFM height images. In these frames, the total number of counts was 100 , respectively.

\section{Figure S-3}

Distribution histograms of the interval (b4) between fiber-like crystals in melt-crystallized thin films of $\mathrm{P}(3 \mathrm{HB}) \quad(\mathrm{A}), \quad \mathrm{P}(3 \mathrm{HB}-c o-3 \mathrm{~mol} \% \quad 3 \mathrm{HH}) \quad(\mathrm{B})$, $\mathrm{P}(3 \mathrm{HB}-c o-8 \mathrm{~mol} \%$ 3HH) (C), $\mathrm{P}(3 \mathrm{HB}-c o-10 \mathrm{~mol} \%$ 6HH) (D), $\mathrm{P}(3 \mathrm{HB}-c o-6 \mathrm{~mol} \%$ 3HV) (E), and $\mathrm{P}(3 \mathrm{HB}-c o-14 \mathrm{~mol} \% 3 \mathrm{HV})(\mathrm{F})$ after enzymatic degradation for $2 \mathrm{~h}$ by $\mathrm{PHB}$ depolymerase from $R$. pickettii $\mathrm{T} 1$ at $20{ }^{\circ} \mathrm{C}$. Each interval was measured from AFM height images. In these frames, the total number of counts was 100, respectively.

\section{Figure S-4}

Thickness (c0-c3) distribution histograms of fiber-like crystals in melt-crystallized thin films of $\mathrm{P}(3 \mathrm{HB})(\mathrm{A}), \mathrm{P}(3 \mathrm{HB}-c o-3 \mathrm{~mol} \% \quad 3 \mathrm{HH})$ (B), $\mathrm{P}(3 \mathrm{HB}-c o-8 \mathrm{~mol} \% 3 \mathrm{HH})$ (C), $\mathrm{P}(3 \mathrm{HB}-c o-10 \mathrm{~mol} \% 6 \mathrm{HH})(\mathrm{D}), \mathrm{P}(3 \mathrm{HB}-c o-6 \mathrm{~mol} \% 3 \mathrm{HV})(\mathrm{E})$, and $\mathrm{P}(3 \mathrm{HB}-c o-14 \mathrm{~mol} \%$ $3 \mathrm{HV}$ ) (F) after enzymatic degradation for $2 \mathrm{~h}$ by PHB depolymerase from $R$. pickettii $\mathrm{T} 1$ at $20{ }^{\circ} \mathrm{C}$. The frames $(\mathrm{A}-\mathrm{F}(\mathrm{c} 0))$ were measured the thickness of flat-on lamellar crystals by AFM before enzymatic degradation. The frames (A-F(c1)), frames (A-F(c2)), and frames (A-F(c3)) were measured the thickness at root, middle, and tip of fiber-like crystals after enzymatic degradation for $2 \mathrm{~h}$ by PHB depolymerase from $R$. pickettii $\mathrm{T} 1$ at $20{ }^{\circ} \mathrm{C}$, respectively. Each thickness was determined from AFM height images. In these frames, the total number of counts was 100, respectively. 


\section{Figure S-5}

Histograms of the width data of fiber-like crystals and crystal size in Table 2. (A): $\mathrm{P}(3 \mathrm{HB}), \quad(\mathrm{B}): \quad \mathrm{P}(3 \mathrm{HB}-c o-3 \mathrm{~mol} \% \quad 3 \mathrm{HH}), \quad(\mathrm{C}): \quad \mathrm{P}(3 \mathrm{HB}-c o-8 \mathrm{~mol} \% \quad 3 \mathrm{HH}), \quad(\mathrm{D}):$ $\mathrm{P}(3 \mathrm{HB}-c o-10 \mathrm{~mol} \%$ 6HH), (E): $\mathrm{P}(3 \mathrm{HB}-c o-6 \mathrm{~mol} \% 3 \mathrm{HV})$, and (F): $\mathrm{P}(3 \mathrm{HB}-c o-14 \mathrm{~mol} \%$ 3HV). Widths of the fiber-like crystals at the root, middle, and tip after enzymatic degradation for $2 \mathrm{~h}$ were measured from AFM, whereas the crystal sizes were determined from the (020) reflection in WAXD data.

\section{Figure S-6}

Histograms of the thickness data in Table 3. AFM measurements have provided the thickness data of the lamellar crystal before enzymatic degradation and fiber-like crystal at the root, middle, and tip after enzymatic degradation for $2 \mathrm{~h}$. Long period $\left(L_{\mathrm{p}}\right)$ and lamellar thickness $\left(l_{\mathrm{c}}\right)$ were determined by SAXS. 

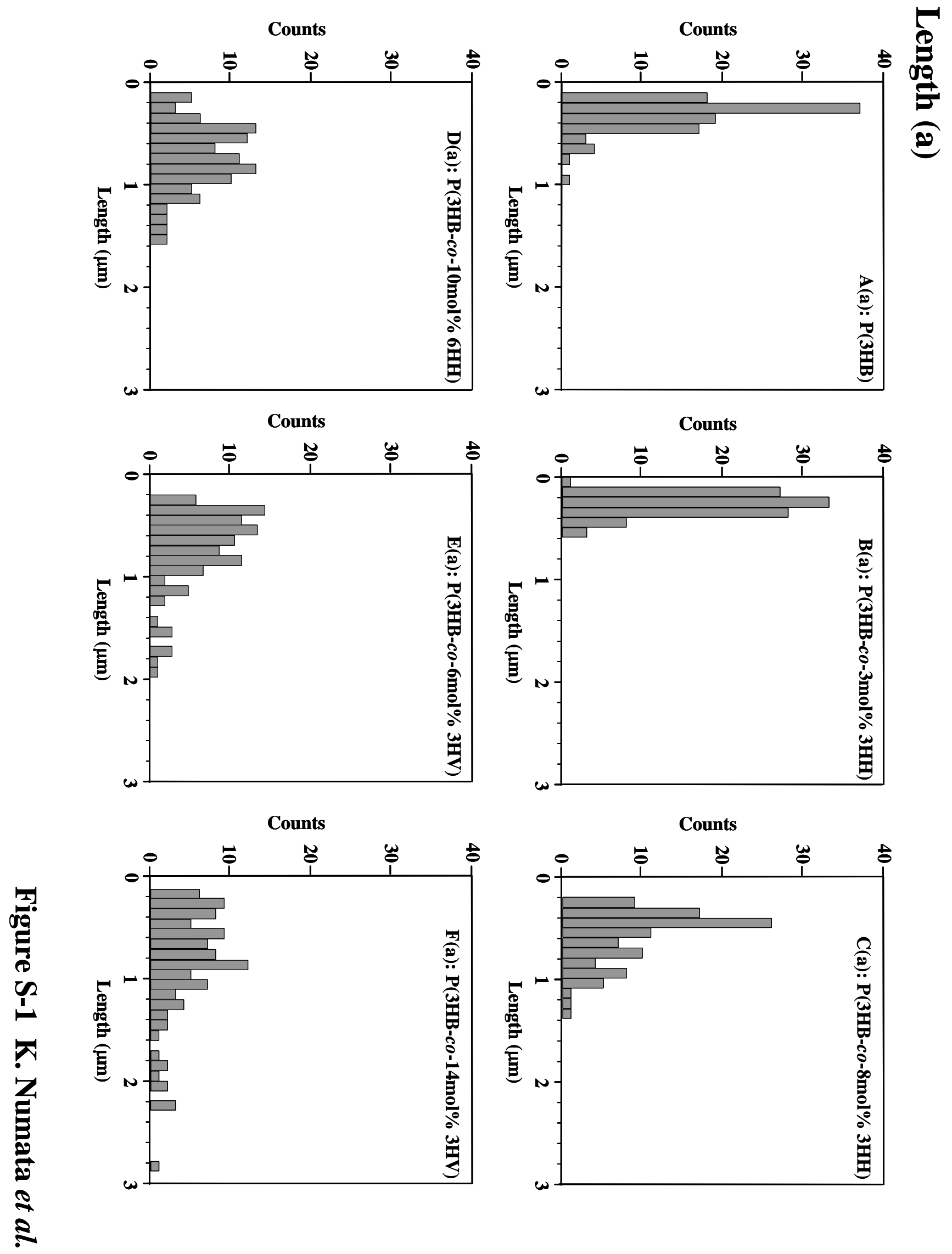


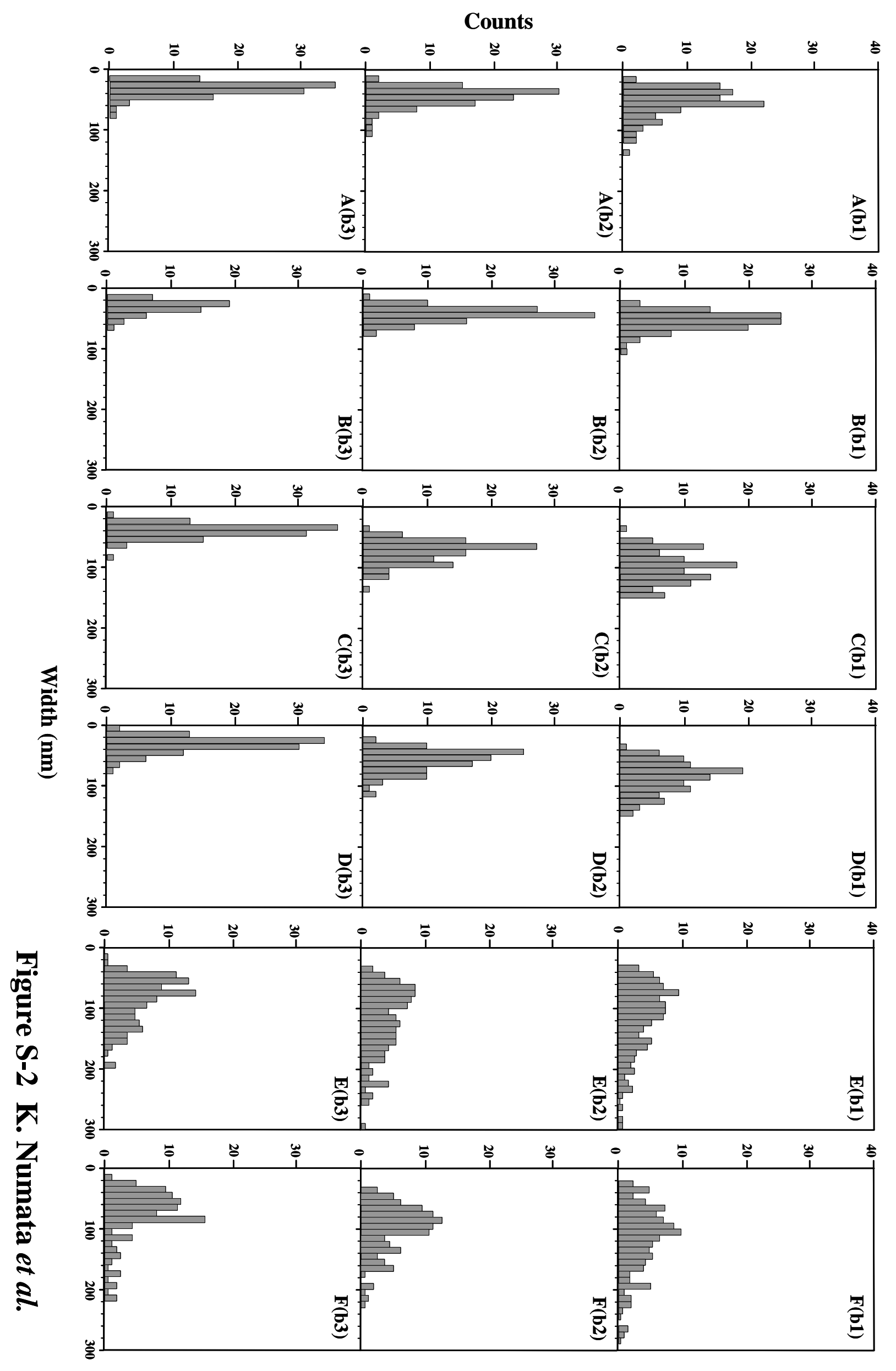

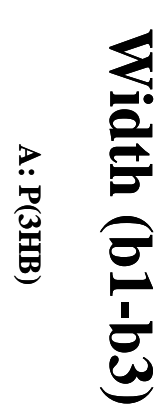

تَّْ

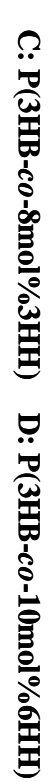

 

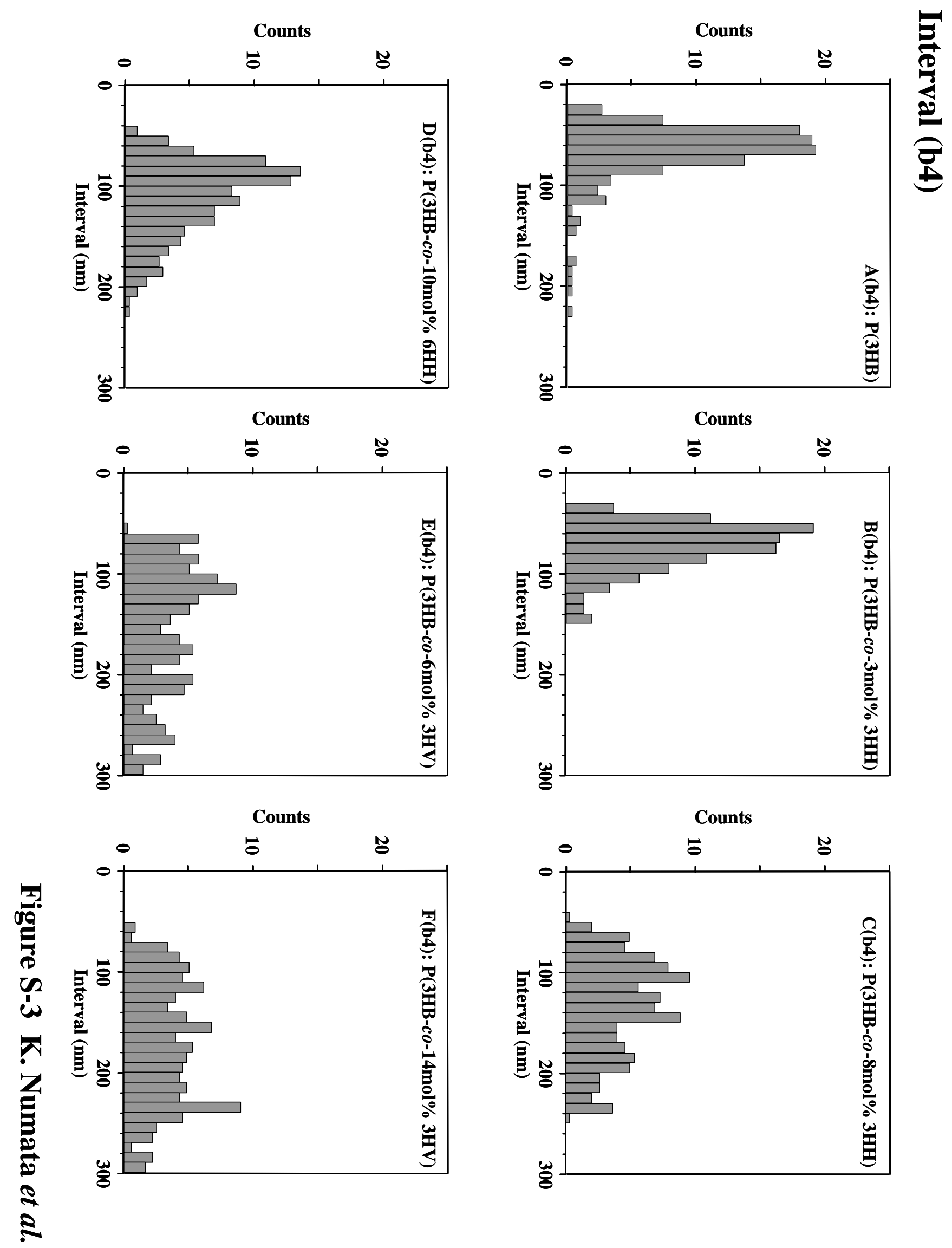


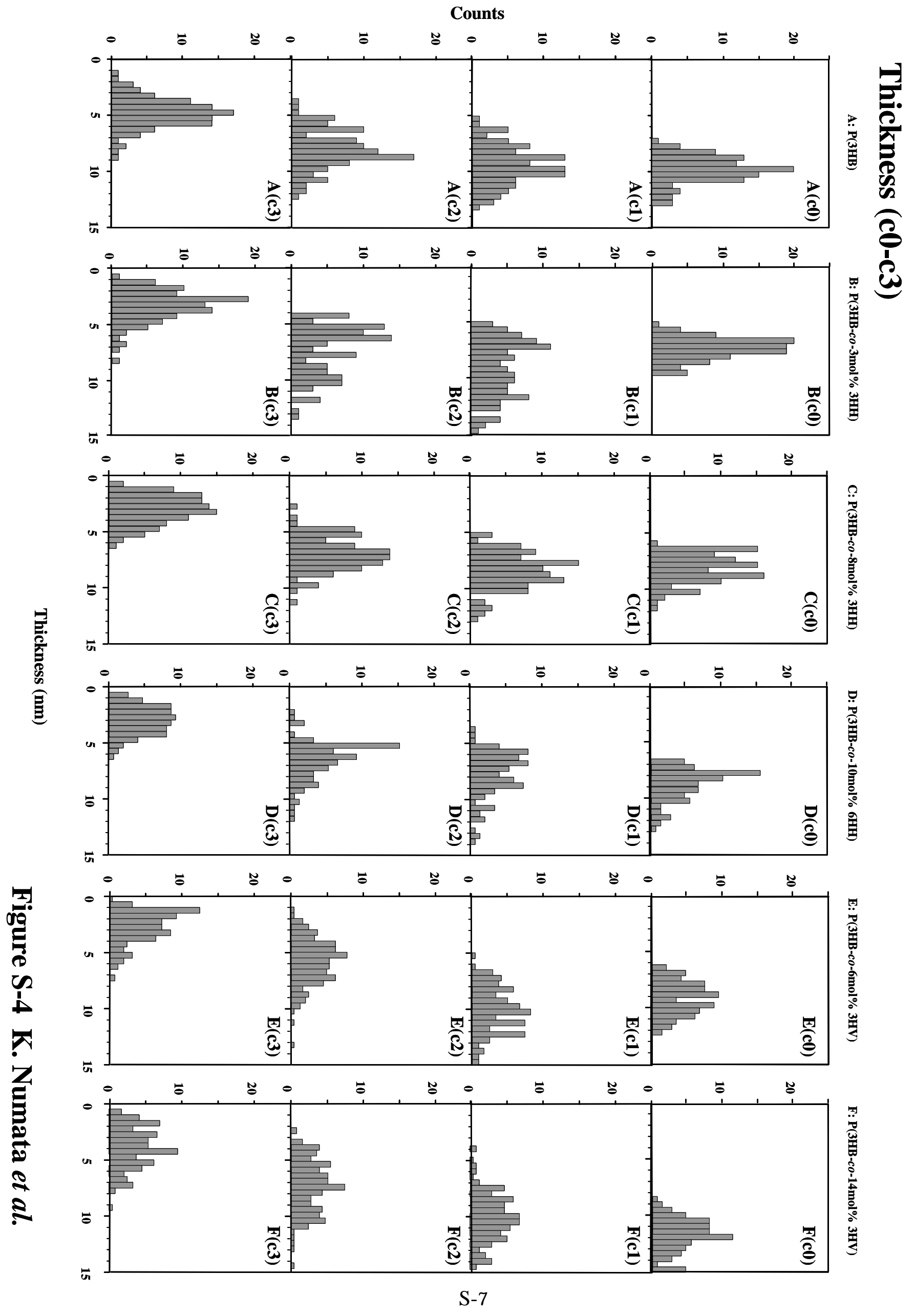



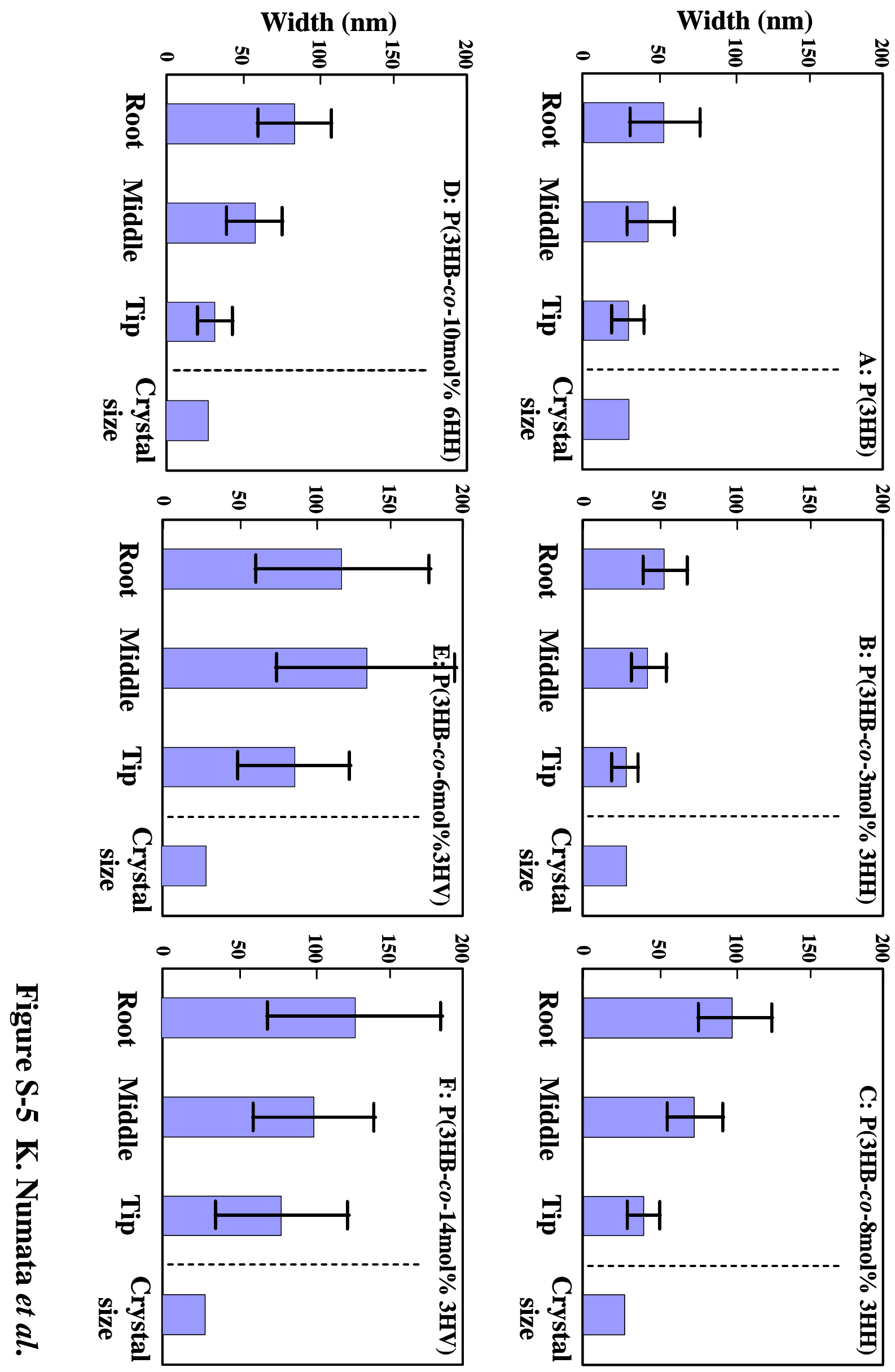


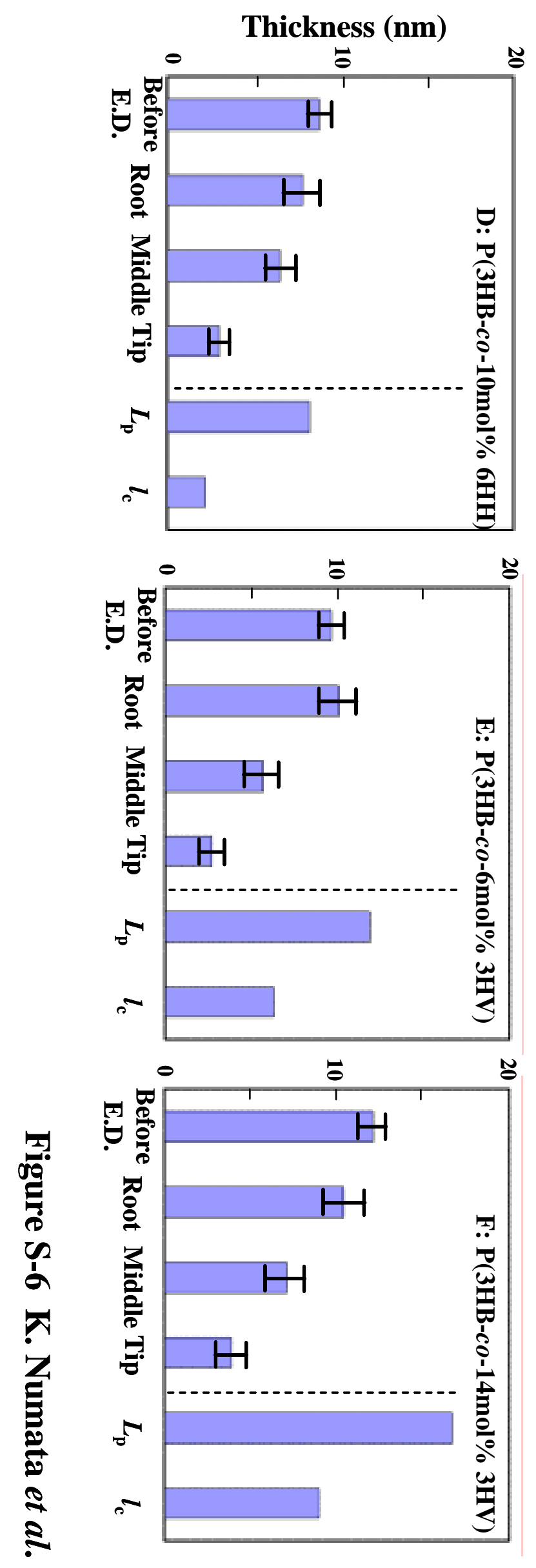

Thickness (nm)
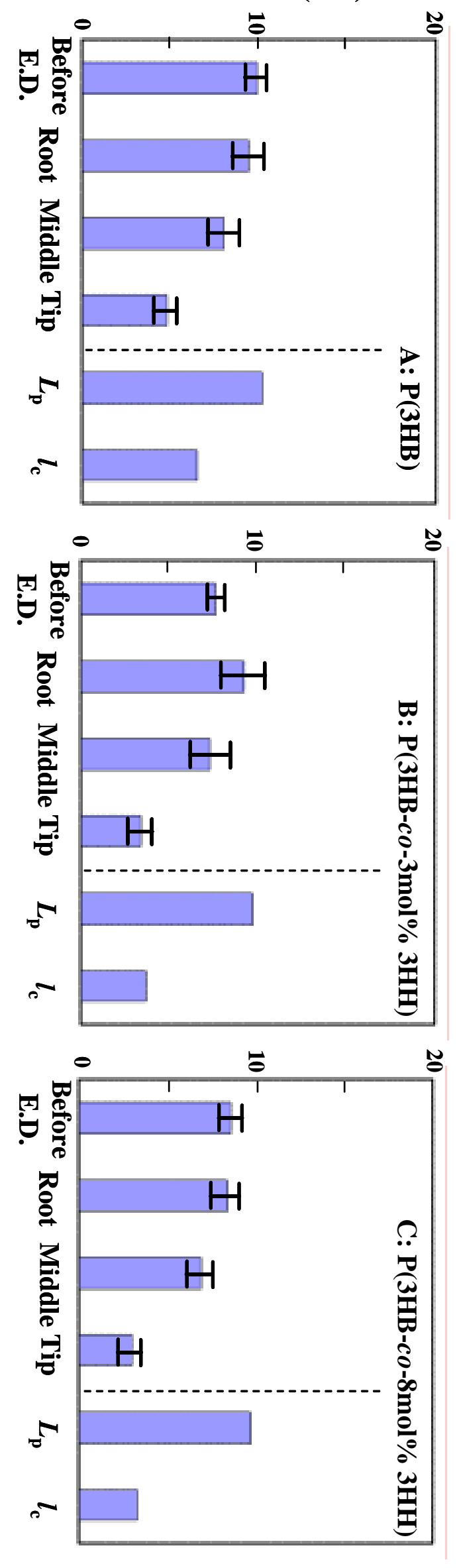